metabolite such as 4-pentenoyl-CoA would be limited by the amount of CoA present in the liver. Since the liver extract has to be so diluted in the final assay for OTC, there might not be enough CoA to form inhibitory concentrations of pentenoylCoA. Thus, the experiments reported here might not have detected a reversable inhibition, but should have detected a nonreversable inhibition of OTC by a metabolite of 4-pentenoate.

On the other hand, it has been shown that both succinate and oligomycin plus dinitrophenol (which makes exogenous ATP available) totally reverse the inhibition of mitochondrial citrulline synthesis caused by 4-pentenoate (2). It seems unlikely that these compounds would reverse a direct enzyme inhibition. (We would like to interject a hope for extreme caution in any attempt to apply this reversal by succinate to the clinical situation of Reye's syndrome.)

Finally, the deficiencies in the assay methods used by Sinatra et al. (4) (and by Thaler et al. (6), since they used essentially the same assay) make it difficult to evaluate abnormalities of OTC reported in patients with Reye's syndrome. Apparently OTC activity is reduced in Reye's syndrome but the reported kinetic abnormalties are in question. In these studies it should be noted that it is not so much the results for patients with Reye's syndrome that are in error (although some probably are), but the results for controls that are in error.

\section{CONCLUSION}

No effect of 4-pentenoate on rat liver ornithine transcarbamylase was demonstrated in this study. It is concluded that technical errors caused other investigators to conclude that a metabolite of 4-pentenoic acid inhibits ornithine transcarbamylase.

\section{REFERENCES AND NOTES}

1. Cleland K. W., and Slater, E. C.: Respiratory granules of heart muscle. Biochem. J. 53: 547 (1973).

2. Glasgow, A. M., and Chase, H. P.: Effect of pent-4-enoic acid, propionic acid and other short-chain fatty acids on citrulline synthesis in rat liver mitochondria. Biochem J., 156: 301 (1976).

3. Glasgow, A. M., and Chase, H. P.: Production of the features of Reye's syndrome in rats with 4-pentenoic acid. Pediat. Res., 9: 133 (1975).

4. Sinatra, F., Yoshida, T., Applebaum, M., Mason, W., Hoogenraad, N. J. and Sunshine, P.: Abnormalities of carbamyl phosphate synthetase and ornithine transcarbamylase in liver of patients with Reye's syndrome. Pediat. Res., 9: 829 (1975).

5. Snodgrass, P. J.: The effects of $\mathrm{pH}$ on the kinetics of human liver ornithinecarbamyl phosphate transferase. Biochemistry, 7: 3047 (1968).

6. Thaler, M. M., Hoogenraad, N. J., and Boswell, M.: Reye's syndrome due to novel protein-tolerant variant of ornithine transcarbamylase deficiency. Lancet, ii: 438 (1974).

7. Requests for reprints should be addressed to: A. M. Glasgow, M.D., Children's Hospital National Medical Center, 2125 13th St. N.W., Washington, D.C. 20009 (USA).

8. Received for publication March 3, 1976

9. Accepted for publication September 9, 1976.

$\begin{array}{ll}\text { DNA } & \text { lung } \\ \text { embryo, chick } & \text { Pneumocystis carinii } \\ \text { epithelial lung cells } & \text { RNA }\end{array}$

\title{
Propagation of Pneumocystis carinii in Vitro
}

\author{
LINDA L. PIFER, WALTER T. HUGHES, ${ }^{(55)}$ AND MARTIN J. MURPHY, JR. \\ Infectious Diseases Service, St. Jude Children's Research Hospital, Memphis, Tennessee, USA
}

\begin{abstract}
Summary
Pneumocystis carinii was propagated in vitro with primary embryonic chick epithelial lung (CEL) cells. Viability and growth of the organism were demonstrated by direct observation of the reproductive cycle in the Sykes-Moore chamber, serial passage with an increase in the number of mature cyst forms, the cytopathic effect of the organism on cell culture, and inhibition of growth of the organism by specific antiserum and pentamidine isethionate. Attempts to culture $P$. carinii indefinitely were not successful. However, cyst forms derived from murine and human sources increased 100-fold and 10-fold, respectively, during CEL cell culture passages. Serial passage of trophozoites alone resulted in the development of typical CPE and a maximum number of $2.8 \times 1^{3}$ cyst forms. Autoradiographic methods demonstrated active DNA, RNA, and protein synthesis within the cyst and suggest that metabolic interaction between the host cells and the organisms occurred. The nature of the attachment of $P$. carinii to the host CEL cell was clearly discernible by scanning electron microscopy (SEM).

In the reproductive cycle a vegetative cell (designated "trophozoite") attached by tubular expansions to the host CEL cell, probably for the transport of essential nutrients, and then de-
\end{abstract}

tached without entering the cell. Sporozoites developed within the detached young cyst, reaching a maximum number of eight within the mature cyst. Excystment occurred through single or multiple sites in the cyst wall, after which the released trophozoite attached to a new host cell.

\section{Speculation}

The in vitro propagation of $P$. carinii provides a basis for further studies to characterize the biologic and biochemical features of this organism and a source of antigen for the development of serologic tests for specific antibody by which the epidemiology and spectrum of clinical disease can be delineated more clearly.

$P$. carinii is a cause of diffuse alveolar disease and interstitial plasma cell pneumonitis (36). Latent infection may occur in the lungs of man and lower animals. Active pneumonitis can be provoked by immunodeficient states or immunosuppressive therapy (18).

This organism was first described in 1909 by Chagas from light microscopic observations of guinea pig lungs infected with Try- 
panosoma cruzi (7). In 1910 Carini (6) found the same agent in the lungs of rats infected with Trypanosoma lewisi and Walker (38) in 1912 discovered the parasite in guinea pigs infected with Trypanosoma evansi. Initially all these authors considered the organism as a developmental stage of trypanosomes. However, Delanoe and Delanoe $(14,15)$ discovered the parasite in lungs of rats and guinea pigs not infected with trypanosomes and proposed the independent genus and species, $P$. carinii. Chagas, Carini, and others subsequently ascertained that $P$. carinii was unrelated to trypanosomes.

Several investigators have attempted to isolate and cultivate $P$. carinii. In 1954 Csillag and Brandstein $(11,12)$ reported the isolation and cultivation of a fungus of the genus Saccharomyces from the lungs of infants with interstitial pneumonia which they believed to be $P$. carinii because mice challenged with the organism via the respiratory route developed pneumonitis, and transient octosporous forms resembling $P$. carinii were seen in the lungs. However, the pulmonary lesions were not wholly identical with those of $P$. carinii pneumonitis (10). Simon (32) proposed that $P$. carinii cysts are vegetative forms of Candida since he regularly cultured these species from the lungs of patients with interstitial plasma cell pneumonia. These studies have not provided convincing proof that the fungi isolated were $P$. carinii. Lung aspirate or autopsy specimens from over 100 cases of $P$. carinii pneumonitis at St. Jude Children's Research Hospital have been cultured on Sabouraud's dextrose media and brainheart infusion agar without obtaining evidence of an ascosporous yeast. Furthermore, we have been unable to culture the organism from infected human and rat lung specimens in any of several other mycologic media, WI-38 cells, L cells, rat lung, and tracheal ring organ cultures. Other attempts to propagate $P$. carinii in artificial media, embryonated eggs, and tissue cultures have failed $(19,31)$.

Since $P$. carinii has not been propagated in vivo or in vitro heretofore, descriptions have been limited to morphologic and tinctorial characteristics derived from microscopic observations of the organism in infected lung tissue $(22,35)$. One form of the organism is a thick walled "cyst" which may be spherical, crescent-shaped, or may appear to be partially collapsed or folded. Some cysts are empty shells and others contain as many as eight intracystic structures, often referred to as "sporozoites." In addition to cysts, thin walled, highly pleomorphic forms, designated "trophozoites" by many authors, have been observed regularly.

The taxonomy of $P$. carinii has not been determined, its natural habitat is unknown, the mode of transmission has not been firmly established, and the extent of subclinical or atypical forms of the disease in man has not been investigated. Basic to further definitive studies of $P$. carinii pneumonitis is the availability of the causative agent in vitro from which specific antigens can be obtained for the development of serologic antibody tests and skin tests. With such tests it may be possible to delineate the epidemiology and to establish the diagnosis of the disease without the hazardous invasive methods required now.

This report describes the isolation and propagation of $P$. carinii in vitro using chick embryo epithelial lung cell cultures.

\section{MATERIALS AND METHODS}

\section{SOURCE OF ORGANISMS}

$P$. carinii organisms were obtained from the lungs of SpragueDawley rats which had been treated with cortisone acetate to provoke infection (22). After rats were killed with sodium Pentothal, the lungs were aseptically removed and shaken vigorously in $25-50 \mathrm{ml}$ of ice-cold calcium and magnesium-free, phosphatebuffered saline (CMF-PBS) (25) supplemented with penicillin $(500$ units $/ \mathrm{ml})$, streptomycin $(0.1 \mathrm{mg} / \mathrm{ml})$, nystatin $(25$ units/ $\mathrm{ml})$, and amphotericin B $(1.2 \mu \mathrm{g} / \mathrm{ml})$. The tissue was allowed to settle and the supernatant containing the organisms was de- canted and centrifuged at $13,200 \times g$ for $10 \mathrm{~min}$ in a Sorvall HB4 rotor $(40)$ at $4^{\circ}$. The pellet was washed repeatedly with CMFPBS to remove debris and suspended in medium 199 (M-199) (41) containing the antibiotics. All preparations were thoroughly mixed on a device with vortex action to obtain a homogeneous suspension of organisms. Lungs from healthy rats examined and found to be free of $P$. carinii were treated in the same manner to prepare a mock inoculum for control cultures. Lung specimens removed at autopsy from patients with $P$. carinii pneumonitis were prepared similarly.

To determine the number of $P$. carinii cysts in inocula and culture media, 10- $\mu$ l aliquots were applied to microscope slides, allowed to dry, and stained with toluidine blue $O(8)$. This volume covered 540 oil immersion fields (o.i.f.). The total number of cysts contained in 200 o.i.f. was counted and multiplied by the factor of 2.7 to give the number of cysts per $10 \mu \mathrm{l}$. The accuracy of this method was tested using five different cyst preparations and performing triplicate counts. The results of these counts are given in Table 1. This method was used to quantitate all inocula and cultures. Trophozoites could not be accurately counted because of affinity to cluster in masses, pleomorphism and variation in staining characteristics.

The inocula were examined with Gram's stain, cultured for bacteria and fungi, divided into aliquots, and frozen at $-15^{\circ}$. Only inocula free of viable bacteria and fungi were used.

As an additional control a sample of the $P$. carinii inoculum was placed in an autoclave for $30 \mathrm{~min}$ at $120^{\circ}$ at 19 pounds pressure. These killed organisms remained morphologically intact as cysts and were inoculated into CEL cell cultures to determine whether viable organisms are necessary to produce cytopathic effect (CPE).

\section{CELL CULTURES}

Embryonic chick epithelial lung cells were prepared from 14day-old embryonated eggs by successive treatments with $0.25 \%$ pronase $(13,42)$. Whole lungs removed aseptically were rinsed several times with sterile CMF-PBS to remove red blood cells and were transferred directly into pronase without mincing. Since the tissue was intentionally not separated into single cells by pronase, cell concentrations were estimated by counting aggregates of three or more cells. The aggregates of epithelial cells were counted and resuspended in M-199 containing $10 \%$ fetal bovine serum (43) and antibiotics. Cultures were then established in Falcon T-75 flasks (44) at a density of $3.0 \times 10^{5}$ aggregates/12 ml M-199/flask and in Leighton tubes containing coverslips with $5.0 \times 10^{4}$ aggregates of cells in $2.0 \mathrm{ml} \mathrm{M}-199 /$ tube. To adjust $\mathrm{pH}$, each flask was treated with $95 \%$ air-5\% $\mathrm{CO}_{2}$ for $30 \mathrm{sec}$ at a flow rate of $4.0 \mathrm{l} / \mathrm{min}$. All cultures were maintained at $35^{\circ}$ for $24 \mathrm{hr}$ before inoculation. Only primary CEL cultures were utilized in these studies.

One CEL cell culture passage is defined as the 3- or 7-day interval between infection and harvest of the culture unless otherwise indicated. The medium was not changed during this interval and, when harvested, the total contents of the flasks including cells and organisms were pelleted and then resuspended in fresh M-199. These preparations were used immediately after appropriate dilution as inocula for fresh cell cultures or were frozen for later use.

Dilution of the inocula by successive splitting through serial passages to a large number of cultures was used to determine whether growth occurred or whether a seeming increase in cysts was due to counting errors. An inoculum of $9.1 \times 10^{4}$ cysts was propagated for four successive passages utilizing a number of primary CEL cell cultures that increased by a factor of 2 for each successive passage, i.e., 3, 6, 12, and 24 primary cell cultures.

In Leighton tube studies, coverslips and media were withdrawn from replicate cultures at intervals postinoculation. The organisms in the media were pelleted, resuspended, and $10-\mu l$ samples were dried on microscope slides, stained, and counted. 
Coverslips from cultures of corresponding media samples were stained with toluidine blue $\mathrm{O}$, and the cysts in 200 oil immersion fields were counted. These counts were done to determine the relative distribution of cysts between the medium and the cells.

In experiments where trophozoites were separated from cysts the organisms were suspended in $100 \mathrm{ml}$ of CMF-PBS with antibiotics and allowed to stand overnight (about $16 \mathrm{hr}$ ) at $4^{\circ}$ The resulting supernatant contained approximately 10 cysts (< $0.5 \%$ of the total number of cysts in the original preparation) and was virtually all trophozoites. The trophozoites could not be accurately quantitated. The separated trophozoites were inoculated into CEL cultures as previously described and were propagated for three passages without freezing.

The Sykes-Moore chamber (33) was utilized for continuous observation of viable cultures by phase contrast microscopy. CEL cells $\left(2.5 \times 10^{4}\right.$ aggregates in $\left.1.0 \mathrm{ml} \mathrm{M}-199\right)$ were injected into the chambers and maintained in an environment of $95 \%$ air and $5 \% \mathrm{CO}_{2}$ at $35^{\circ}$. After $24 \mathrm{hr}$ of incubation, the medium was withdrawn and the cultures were inoculated with 10,000 cysts in $0.2 \mathrm{ml} \mathrm{M}-199$. Two hours after inoculation, an additional $0.8 \mathrm{ml}$ medium was added. Chambers were then placed in a heating element attached to the stage of a phase microscope with the capability of maintaining the culture at a constant temperature of $35^{\circ}$ during prolonged observations. Phase contrast microscopic observations were also made of uninfected and mock-infected control CEL cell cultures under identical conditions. Single organisms were observed and photographed throughout the life cycle.

\section{CELLFREE CULTURES}

Several cell-free media used in the propagation of other parasites were inoculated with $P$. carinii and maintained at $35^{\circ}$. The systems investigated included Pan's medium developed for the cultivation of $T$. cruzi (29), Newton's medium for Strigomonas oncopelti (27), Diamond's medium for Trypanosoma ranarum (39), NNN medium for T. cruzi (28), Balamuth's egg extract medium for Entamoeba histolytica (1), Diamond's medium for Trichomonas vaginalis, Trichomonas gallinae, and Trichomonas hominis (16), Blair's medium for T. cruzi and Leishmania donovani (4), Chang's medium for hemoflagellates (9), Tobie's medium for Trypanosoma rhodesiense and Trypanosoma gambiense (34), and Schaedler's broth for fastidious organisms (45).

\section{IDENTIFICATION OF P. CARINII}

In addition to toluidine blue $O$, Gomori's methenamine silver nitrate, Giemsa, and polychrome methylene blue stains (22), the indirect fluorescent antibody (IFA) technique was utilized to further substantiate that the organism maintained in culture was $P$. carinii. Organisms harvested after three serial passages in CEL cell cultures were separated in sucrose density gradients according to the method of Lim et al. (23). Ten microliters of medium containing approximately 200 organisms/o.i.f. were dried on microscope slides. The slides were fixed in absolute methanol for $20 \mathrm{~min}$ and then dried and stored at $-70^{\circ}$. Sera containing antibody to $P$. carinii in titers of $1: 16$ and $1: 64$, respectively, by the IFA method were obtained from the $\mathrm{Na}$ tional Center for Disease Control as well as from patients at St. Jude Children's Research Hospital during acute and convalescent phases of $P$. carinii pneumonitis. Antisera absorbed with $P$. carinii-infected rat lung were used for controls. The IFA test was done according to the method of Fletcher (17) using goat antihuman immunoglobulin $G$ conjugated with fluorescein isothiocyanate $(3.4 \mathrm{mg}$ antibody protein/ml, O.D. $280 \mathrm{~nm} / 495 \mathrm{~nm}=1.1)$ (46). Buffered glycerol at $\mathrm{pH} 8.0$ was applied to slides, coverslips were added, and the preparation was examined immediately.

Pentamidine isethionate (47), an agent known to be effective in the treatment of $P$. carinii infection, was prepared in concen- trations of $0.3,1.0,3.0$, and $9.0 \mu \mathrm{g} / \mathrm{ml}$ of medium. CEL cell cultures were re-fed with medium containing the respective drug concentrations $2 \mathrm{hr}$ after inoculation with $5.4 \times 10^{4} \mathrm{P}$. carinii cysts. To determine possible drug-induced CPE, noninfected control cultures received identical concentrations of pentamidine. Infected control cultures received no drug. Cyst counts were done at intervals over a period of $72 \mathrm{hr}$.

The inhibitory effect of specific antisera on the growth of $P$. carinii in culture was studied using human sera with a $P$. carinii IFA titer of 1:512. Aliquots of third passage $P$. carinii cysts were incubated with human antisera, with human serum containing no detectable antibody, and with fetal bovine serum, respectively, for $2 \mathrm{hr}$ at $37^{\circ}$ and then inoculated into CEL cultures. Each culture received $8.0 \times 10^{4}$ cysts. Cyst counts were made of the three series of cultures at intervals over a period of 3 days

The viability and relationship of $P$. carinii to host cells in culture were investigated by autoradiography. Separate cultures with monolayers of CEL cells were established in M-199 containing $20 \mu \mathrm{Ci} / \mathrm{ml}$ of $\left[{ }^{3} \mathrm{H}\right]$ thymidine $\left(\left[{ }^{3} \mathrm{H}\right] \mathrm{TdR}\right)(\mathrm{sp}$. act. $=6$ $\mathrm{Ci} / \mathrm{mM}),\left[{ }^{3} \mathrm{H}\right]$ uridine $\left(\left[{ }^{3} \mathrm{H}\right] \mathrm{UR}\right)(\mathrm{sp}$. act. $=21 \mathrm{Ci} / \mathrm{mM})$, and ${ }^{3} \mathrm{H}-$ labeled amino acids $(\mathrm{sp}$. act. $=0.26-53 \mathrm{Ci} / \mathrm{mM})(47)$. respectively. After $48 \mathrm{hr}$ of incubation, the monolayers were thoroughly rinsed with CMF-PBS to remove the unincorporated label and unattached cells and were infected with $3 \times 10^{3} P$. carinii cysts/T-75 flask of $2 \times 10^{7} \mathrm{CEL}$ cells. The cultures were supplemented with M-199, without isotope labels. at 2 hr postinfection. Supernatants containing cysts from these cultures were decanted at $48 \mathrm{hr}$ postinfection and the organisms were washed thoroughly with CMF-PBS until no radioactivity remained (sucrose gradients, washed, dried, and fixed on slides for light microscopy autoradiography.) The slides were dipped in Kodak nuclear track emulsion (49) exposed in the dark at $4^{\circ}$ for 5 days and then developed. Representative slides from each group were prestained with toluidine blue $O$ to permit specific identification of $P$. carinii cysts.

\section{SCANNING AND TRANSMISSION ELECTRON MICROSCOPY}

$P$. carinii organisms obtained from infected rat lungs were inoculated into 24-hr-old CEL monolayers grown to approximately $80 \%$ confluency on sterile $12-\mathrm{mm}$ mica discs. The mica discs bearing the attached infected cells were withdrawn from cultures at various times between 4 and $38 \mathrm{hr}$ after inoculation and processed for SEM. Uninfected CEL cell cultures prepared in the same manner but using uninfected rat lung tissue as a mock inoculum were used as controls. The mica discs were rinsed briefly in saline then fixed by immersion in chilled $4 \%$ glutaraldehyde in $0.1 \mathrm{M}$ phosphate buffer at $\mathrm{pH} 7.4$ for $1-3 \mathrm{hr}$ at $4^{\circ}$. They were then washed twice in phosphate buffer, postfixed for $1-3 \mathrm{hr}$ with $1.0 \% \mathrm{OsO}_{4}$ in $0.2 \mathrm{M}$ phosphate buffer, and finally washed twice with distilled water. Tissue dehydration and embedding in Epon-812 were done by the method of Luft (24). An LKB Ultratome and diamond knife were used to cut a series of alternate thick and thin sections (26). The thick sections were placed on glass slides and examined by light microscopy. The thin sections were mounted on Formvar-coated 75-mesh copper grids and stained with uranyl acetate and lead acetate. Some specimens were stained en bloc with uranyl acetate at the step immediately preceding $\mathrm{OsO}_{4}$ postfixation according to the method of Schoefl (30). The ultrathin sections were examined in a Siemens electron (50) microscope $1 \mathrm{~A}$ at $80 \mathrm{kv}$. A Philips SEM500 scanning electron micoscope (51) operated at $25 \mathrm{kvp}$ was used for the scan observations.

\section{PHOTOMICROGRAPHY}

Phase contrast photomicrographs were made with a LeitzWetzler 51 microscope using Kodak plus-X film in an orthomat camera. 


\section{RESULTS}

In the culture system to be described the following terms will be used for stages in the life cycle of $P$. carinii. "Sporozoite" refers to the intracystic bodies. At a point where and when the sporozoite is released from the cyst the term trophozoite will be applied. The "trophozoite" is the extraeystic form originating from the point of excystment and extending throughout its attachment to the host cell. "Cyst" will refer to the organism at the time the trophozoite detaches from the host cell.

\section{QUANTITATION OF CYSTS}

As shown in Table 1, the method for quantitation of cysts was highly reproducible. Based on a one-way analysis of variance, a $95 \%$ confidence interval for the unknown standard deviation is from approximately 12 to just over 30 . Thus, a difference between two successive slide counts in excess of $60 \mathrm{cysts} / 10 \mathrm{\mu l}$ would be sufficient to establish a significant change in the number of cysts. The observed cyst counts in these studies are substantially above changes that could be reasonably attributed to measurement error.

\section{PROPAGATION OF P. CARINII IN CEL CELL CULTURES}

Dependent upon the number of organisms in the inoculum, a cytopathic effect (CPE) was observed within 24-72 hr after inoculation with $P$. carinii cysts and trophozoites or trophozoites alone from rat or human sources. Flask cultures inoculated with $9 \times 10^{4}$ cysts contained a ratio of about 1 cyst to $200 \mathrm{CEL}$ cells and focal areas of CPE were evident about $48 \mathrm{hr}$ postinoculation. The cells became rounded, vacuolated, and sloughed from the monolayer in degenerate patches. Surrounding cells lost the epithelial appearance and became small, elongated, and stringlike. The few fibroblasts were remarkably resistant to morphologic alteraton. Maximum CPE occurred during serial passages where increase in the number of both murine- and humanderived organisms was greatest. Likewise, as the net yield of cysts began to decline during later passages, a concomitant decrease in CPE was observed.

More than $4 \times 10^{6}$ cysts $/ 2.4 \times 10^{7}$ cells resulted in complete destruction of the monolayer. Likewise, dilution of the original inoculum to less than $1 \times 10^{3}$ cysts $/ 2.4 \times 10^{7}$ cells resulted in failure to establish productive infection. No CPE occurred in control cultures inoculated with normal rat lung washings or with heat-killed $P$. carinii.

For serial passages, the total number of $P$. carinii organisms those in the medium and host cell associated, were harvested from the flask cultures at 3 or 7 days postinoculation, concen-

Table 1. Quantitation of Pneumocystis carinii cysts

\begin{tabular}{cccc}
\hline $\begin{array}{c}\text { Specimen } \\
\text { preparations }\end{array}$ & $\begin{array}{c}\text { Triplicate counts } \\
\text { (cysts/10 } \mu \text { l) }\end{array}$ & Mean \pm SD & $\begin{array}{c}\text { Coefficient } \\
\text { of variation, } \\
\%\end{array}$ \\
\hline \multirow{2}{*}{$\begin{array}{c}2,268 \\
2,252\end{array}$} & $2,268 \pm 16$ & 0.7 \\
& 2,284 & & \\
2 & 1,458 & $1,459 \pm 10$ & 0.7 \\
& 1,450 & & \\
& 1,469 & $933 \pm 13$ & 1.4 \\
3 & 948 & & \\
& 929 & $1,481 \pm 12$ & 0.8 \\
4 & 923 & & \\
& 1,469 & & \\
5 & 1,492 & $2,047 \pm 32$ & \\
& 1,482 & & \\
\hline
\end{tabular}

Table 2. Serial passage at 3-day intervals of Pneumocystis carinii ${ }^{1}$

\begin{tabular}{ccc}
\hline Passage no. & Day of passage & Total no. cysts/passage \\
\hline 0 & 0 & $2.7 \times 10^{5}$ \\
1 & 3 & $5.5 \times 10^{6}$ \\
2 & 6 & $1.4 \times 10^{7}$ \\
3 & 9 & $1.5 \times 10^{7}$ \\
4 & 12 & $2.3 \times 10^{7}$ \\
\hline
\end{tabular}

1 Derived from rat lung.

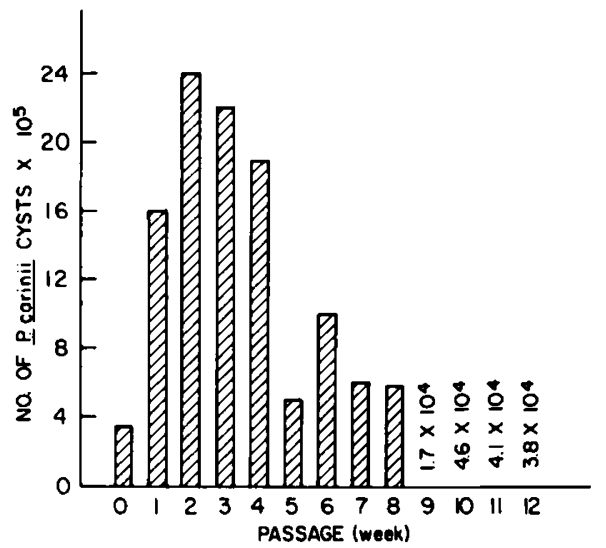

Fig. 1. Serial passage of murine Pneumocystis carinii in chick epithelial lung cell cultures. With each passage, organisms were cultured for 3 days, harvested, counted, and stored for 4 days at $-15^{\circ}$. The organisms were then thawed and reinoculated into fresh chick epithelial lung cells. The bars represent the total number of $P$. carinii cysts per passage

trated by centrifugation, resuspended in fresh M-199, and used in toto as the inocula for fresh cell cultures. M-199 was never changed during a passage but was always changed at the beginning of a new passage. The results of four serial passages in culture of $P$. carinii derived from rat lungs are given in Table 2 . Continuous passage at 3-day intervals over a period of 12 days without freezing between passages resulted in an increase in the number of cysts from $2.7 \times 10^{5}$ to $2.3 \times 10^{7}$. $P$. carinii from human sources has been maintained through five passages at 7 day intervals without freezing with increase in the number of cysts from $5 \times 10^{3}$ to $7.6 \times 10^{4}$.

In other experiments, when $P$. carinii organisms of rat origin were harvested after 3 days in CEL cultures, stored at $-15^{\circ}$ for 4 days, and reinoculated into fresh cell cultures, an increase in the number of cyst forms occurred with the first and second passages (Fig. 1). After the initial inoculation of $3.0 \times 10^{5}$ cysts, a peak titer of $2.4 \times 10^{6}$ cysts was reached with the second passage. The yield from subsequent passages was progressively less, and by passage 8 the yield was only twice the number in the initial inoculum.

The results of studies to dilute the original inoculum by serial passages into multiples of cultures are summarized in Table 3. After serial passages from the single inoculum through 24 separate cultures in the fourth passage, a 16-fold increase in the number of cysts occurred. A cytopathic effect occurred throughout the four passages.

The relative distribution of $P$. carinii cysts between the medium and the CEL cells in Leighton tube cultures for one passage is depicted in Figure 2. In this system $P$. carinii cysts were found free and in abundance in the media and also associated with CEL cells on the coverslips. The cysts were not found intracellularly as determined by light microscopy, but were directly adjacent to host cells. This relationship will be described later from serial observations in the Sykes-Moore chamber. The number of organisms associated with the host cells on coverslips and the number in the media, determined separately with inocula of $8 \times 10^{3}$ cysts, $38 \times 10^{3}$ cysts, and $76 \times 10^{3}$ cysts, 
respectively, are plotted. These counts were determined from harvests of replicate cultures. The number of cysts associated with the host cells did not increase until more than $120 \mathrm{hr}$ postinoculation. However, in the media, a rapid increase in number of cysts was encountered at $24 \mathrm{hr}$ with the highest inoculum and at $48 \mathrm{hr}$ with the lowest inoculum (Fig. 2). This initial rapid increase was followed by a decline in the number of cysts but never below the inoculum level. A third phase was one of a progressive increase in the number of organisms, more marked at the higher inoculum levels. It is important to point out that only cyst forms of the organism were counted since the trophozoites had a marked affinity for clustering and were difficult to identify and quantitate with either toluidine blue $\mathrm{O}$ or polychrome methylene blue stains.

To determine whether trophozoites give rise to cysts in vitro or whether cysts in the original inoculum are merely being serially transferred from one passage to the next, inocula containing trophozoites with a negligible number of cysts $(<10)$ were passed three times in CEL culture (Table 4). The number of cyst forms increased through two passages and decreased in the third passage; $2.8 \times 10^{3}$ cysts were found in the second passage. For reasons already described, trophozoites were not enumerated. Typical CPE developed in cultures inoculated with trophozoites alone.

To determine whether $P$. carinii requires living cells for growth, CEL cells were frozen at $-15^{\circ}$, thawed, and then inoculated with the organisms. As shown by the control in Figure $2 A$, these cultures did not support growth of the organisms.

Table 3. Serial passage of murine Pneumocystis carinii with dilution of inoculum by split into multiple cultures

\begin{tabular}{cccc}
$\begin{array}{c}\text { Passage } \\
\text { no. }\end{array}$ & $\begin{array}{c}\text { Day of } \\
\text { passage }\end{array}$ & $\begin{array}{c}\text { No. } \\
\text { cultures } \\
\text { (flasks) }^{2}\end{array}$ & $\begin{array}{c}\text { Total no. } \\
\text { cysts/passage }\end{array}$ \\
\hline 0 & 0 & & $9.1 \times 10^{4}$ \\
1 & 3 & 3 & $8.3 \times 10^{5}$ \\
2 & 6 & 6 & $9.3 \times 10^{5}$ \\
3 & 9 & 12 & $9.8 \times 10^{5}$ \\
4 & 12 & 24 & $1.5 \times 10^{6}$ \\
\hline
\end{tabular}

' One passage $=3$ days.

${ }^{2}$ One $75 \mathrm{~cm}^{3}$ flask with $2.4 \times 10^{7}$ primary embryonic chick epithelial lung cells.
Morphologically intact heat-killed $P$. carinii organisms, inoculated onto CEL cells, did not grow and CPE was not apparent.

\section{LIFE CYCLE}

Observations made of CEL cell cultures in Sykes-Moore chambers using phase contrast microscopy revealed that at $2 \mathrm{hr}$ postinoculation, many cell-associated and unassociated organisms varied in size and shape (Fig. 3). There were real differences due to the stage of the life cycle. By continuous viewing of single organisms, the pattern of growth was discernible. The unattached, unicellular organism (trophozoite) with granular cytoplasm and poorly demarcated nucleus (Fig. 3A) became attached to CEL cells either very firmly or loosely by what appeared to be short strand-like "fibers" (Fig. 3B). The average time required for attachment was $30 \mathrm{~min}$. Immediately after attachment to the cells, the organisms diminished slightly in size, and the cytoplasm appeared more transparent with a single, slightly darker nucleus. No other cytoplasmic structures were evident. Trophozoites generally remained attached for about 90 min. At the time of detachment, convolutions were usually apparent and the organism more rounded (Fig. $3 \mathrm{C}$ ). At no time were the organisms observed to enter the host cells. These "fibers" trailing the detached cyst did not appear to have any locomotive function and gradually disappeared. The host cell degenerated. The free-floating cysts increased in size. In doing so, many organisms had convolutions and organized structures (sporozoites) became apparent within the cytoplasm of the cysts during their development (Fig. $3 D$ ). Sporozoites became clearly discernible at $4 \mathrm{hr}$ postinoculation. The exact derivation of these intracystic structures could not be determined with the optical limitations inherent in the Sykes-Moore chamber. The cyst eventually assumed a spherical shape with a thickened cell wall and contained as many as eight spherical, oblong, or crescent-shaped sporozoites. Excystment occurred at single sites (Fig. 3, $E$ and $F$ ) or at multiple sites through the cyst wall. Disruption of the cyst wall was associated with escape of the sporozoite. The newly excysted organism (trophozoite) floated freely in the medium and attached to host CEL cells within $30 \mathrm{~min}$ to $2 \mathrm{hr}$. The parent cyst would continue excystment until complete or continue to enlarge to as much as 6 times the size of the preattachment trophozoite and become dormant or inactive (Fig. $3 G$ ). Complete excystment required $60-90 \mathrm{~min}$. The entire life cycle required from 4-6 hr for completion under the conditions used.
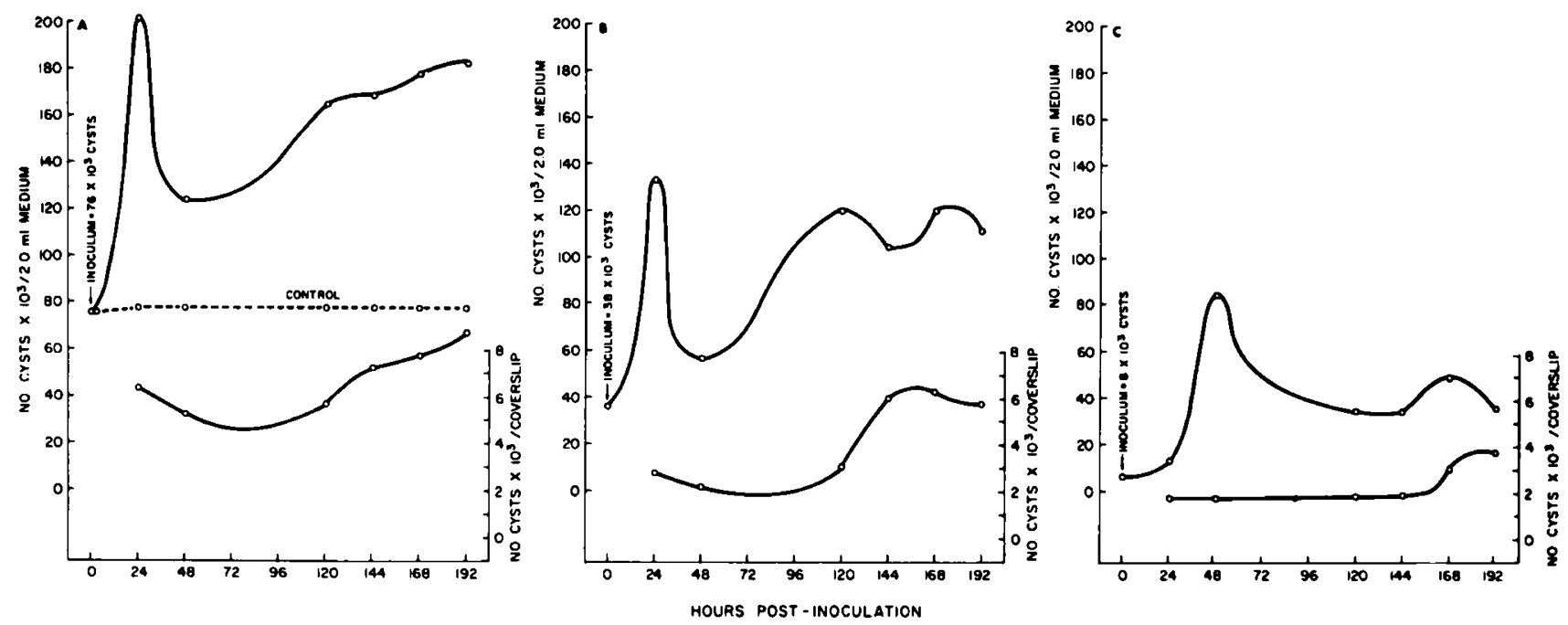

Fig. 2. Growth patterns of Pneumocystis carinii of rat origin in replicate Leighton tube cultures. Upper line on each graph represents the total number of cysts harvested from the culture media while the lower line shows the total number of cysts attached to host chick epithelial lung cells on coverslips (scale on right side of graph). Each pair of corresponding points represents one replicate culture. Replicate cultures were terminated at 1 , $2,5,6,7$, and 8 days to obtain these counts. A: culture inoculated with $76 \times 10^{3}$ cysts. Control cultures were freeze-killed chick epithelial lung cells inoculated with $76 \times 10^{3}$ cysts (- - ). B: cultures inoculated with $38 \times 10^{3}$ cysts. $C$ : cultures inoculated with $8 \times 10^{3}$ cysts. 
Table 4. Serial passage at 3-day intervals of Pneumocystis carinii trophozoites ${ }^{1}$

\begin{tabular}{ccc}
\hline Passage no. & Day of passage & Total no. cysts/passage \\
\hline 0 & 0 & $<10$ \\
1 & 3 & $2.4 \times 10^{3}$ \\
2 & 6 & $2.8 \times 10^{3}$ \\
3 & 9 & $1.5 \times 10^{3}$ \\
\hline
\end{tabular}

' Derived from human lung.

Since cysts remained dormant for varying periods of time and cultures were not synchronous, the growth pattern as shown in Figure 2 is not comparable to the replication of single organisms observed in the Sykes-Moore chamber.

In CEL cell cultures mock infected with normal rat lung inoculum, no structures resembling those described were observed in the Sykes-Moore system. Furthermore, in lung washings from $P$. carinii-infected rats, organisms identical with those observed in cultures were found (Fig. $3 H$ ).

\section{IDENTIFICATION OF P. CARINII}

The organisms in culture were morphologically and tinctorially identical with $\boldsymbol{P}$. carinii cysts, sporozoites, and trophozoites described by others as well as control organisms obtained directly from human and murine cases of $P$. carinii pneumonitis. Figure 4 depicts the organisms after three passages in CEL cell cultures. Using Gomori's method to impregnate the cyst wall and hematoxylin an eosin to stain the CEL cells (Fig. 4A), the characteristic brownish, round, and cup-shaped cysts, about 6 $\mu \mathrm{m}$ in diameter, were seen in relation to the aggregate monolayer. Degeneration of adjacent host cells was seen consistently wherever $P$. carinii cysts were associated with CEL cells. Cysts stained with toluidine blue $O$ (Fig. $4 B$ ) were morphologically similar to those treated by the Gomori method, except that the organisms appeared violet or lavender in color and the host cells were not stained. With polychrome stains the sporozoites were seen as pleomorphic, crescent-shaped, oval, or rounded structures (Fig. $4 C$ ). Up to eight sporozoites were found in a single cyst. The cytoplasm of the sporozoite stained light blue with a dark red nucleus. The trophozoite in culture stained very poorly with extremely faint cytoplasm and cell boundary but had a prominent reddish blue nucleus.

Specific $P$. carinii antiserum completely inhibited the growth of $P$. carinii in CEL cell cultures and as a result almost entirely eliminated CPE (Table 5). Initially, each culture received $8.0 \times$ $10^{4} \mathrm{cysts} /$ culture. Organisms incubated in human sera without antibody to $P$. carinii or in fetal bovine serum exhibited a definite growth pattern whereas growth of organisms incubated in human sera containing antibody to $P$. carinii was inhibited.

In cultures inoculated with $5.4 \times 10^{4}$ cysts and treated with pentamidine isethionate, growth of the organism was inhibited with drug concentrations of $0.3-9.0 \mu \mathrm{g} / \mathrm{ml}$ of media with a cyst yield of only $5.9 \times 10^{4}$ at $48 \mathrm{hr}$ postinoculation. Pentamidine did not appear to alter cell or cyst morphology at these drug concentrations. Appearance of CPE was delayed until about $48 \mathrm{hr}$ postinfection, and at this time was only slightly manifested. Control cultures, in contrast, produced a typical $(12.8-13.8 \times$ $10^{5}$ cysts) yield of organisms.

Indirect fluorescein-tagged antibody to $P$. carinii applied to organisms harvested after three serial passages produced brilliant yellow-green fluorescence extending around the entire periphery of the cyst. Fluorescence was not elicited when the antisera had been absorbed with $P$. carinii-infected lung tissue or when control sera from normal individuals with no detectable antibody were substituted for the $P$. carinii antisera. When Candida albicans was reacted with the $P$. carinii antisera, no fluorescence was observed. Furthermore, in mock-infected control cell cultures, $P$. carinii antisera was nonreactive by the IFA method.
Autoradiographic studies demonstrated the ${ }^{3} \mathrm{H}$-amino acids label as darkened foci distributed diffusely throughout the cyst. The $\left[{ }^{3} \mathrm{H}\right]$ UR label (Fig. 5) was also distributed throughout the cyst but tended to be slightly more prevalent near the periphery of the cyst. The $\left[{ }^{3} \mathrm{H}\right] \mathrm{TdR}$ isotope had a different pattern topographically. The label was seen as larger and clearly demarcated foci at the periphery of the cyst. These areas corresponded to the location of sporozoites on polychrome methylene blue stains. These studies suggested active DNA, RNA, and protein synthesis within the cyst and metabolic interaction between the host cell and the organisms.

\section{ELECTRON MICROSCOPY}

The nature of the attachment of $P$. carinii to the host CEL cell was clearly discernible by SEM. Short pseudopodal extensions (Fig. 6A) and slender, long and individual or thickened and branched (Fig. $6 B$ ) filaments were involved in the attachment of $P$. carinii to the underlying host cells. The extent of penetration of the host cell, if any, could not be determined. Cyst forms, averaging $5 \mu \mathrm{m}$ in diameter, were frequently found with discrete microvilli (Fig. $6 C$ ). Budlike protrusions, 0.7-1.0 $\mu \mathrm{m}$ in diameter, were occasionally noted in some of the larger organisms (Fig. 6D), and may represent sporozoites in the process of excystment. Cup-shaped concave forms, 6-8 $\mu \mathrm{m}$ in diameter (Fig. $6 D$ ), are morphologically comparable to the organisms seen with the Gomori and toluidine blue $O$ stains by light microscopy. The concave organisms shown in Figure $6 D$ may represent the precyst stage before sporozoites are fully developed or may be cysts void of content as a result of excystment of sporozoites. The uninfected control CEL cell cultures were uniformly devoid of any of the organisms seen in the infected cultures.

The ultrastructural features of $P$. carinii in culture were identical with those described from transmission electron microscopy studies of the organism in naturally infected rat and human lungs $(2,5,20,21,37)$. The organisms were distinct from other structures in the CEL cell cultures when comparison was made between infected and uninfected cell cultures. Various phases of the cyst form are depicted in Figure 7, which illustrates a collapsed cyst after excystment of sporozoites (Fig. 7A) and another with an array of intracystic membranes and an apical aggregation of tubular expansions continuous with the cyst wall (Fig. 7B), suggesting recent detachment. At $22 \mathrm{hr}$ in cultivation, more fully developed and mature cysts were predominant (Fig. $7, C$ and $D$ ). The organisms were always adjacent to a complex of the membranous tubular system compatible with that observed by SEM.

\section{CELLFREE CULTURES}

There was no evidence of growth of $P$. carinii in any of the cell-free media tested.

\section{DISCUSSION}

For a limited number of passages, the propagation of $P$. carinii has been achieved in CEL cell cultures as demonstrated by direct observation of the reproductive cycle in the Sykes-Moore chamber, serial passage of cysts and trophozoites and trophozoites alone with resultant increase in the number of mature cyst forms, the gross cytopathic effect of the organism on the cell culture, and inhibition of growth of the organisms by specific antisera and pentamidine isethionate. The isolated agent was identified as $P$. carinii by characteristic tinctorial and morphologic appearance when stained with toluidine blue $O$, Gomori's methenamine silver nitrate, and polychrome methylene blue stains and immunologically by IFA reaction to $P$. carinii antisera.

In serial passage of murine $P$. carinii at 3-day intervals without freezing (Table 2), a 100-fold increase in the number of cyst forms was reached during four passages. In the fourth passage, both titer and CPE reached maximum levels, after which both 

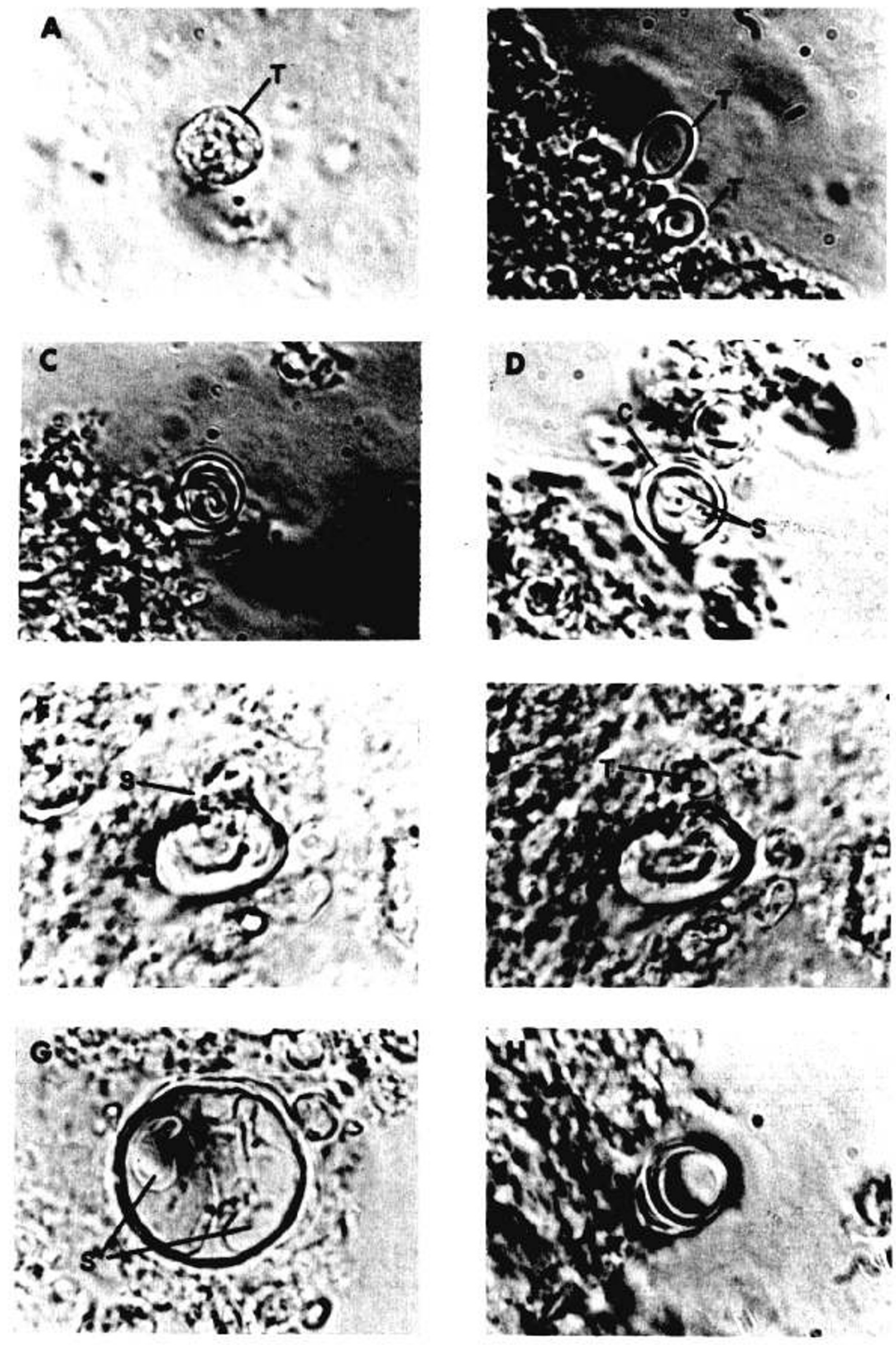

Fig. 3. Continuous observations of Pneumocystis carinii in chick epithelial lung culture in a Sykes-Moore chamber. Phase contrast microscopy (original magnification, $\times 1,250)$. A: unattached, unicellular trophozoite $(T)$; nucleus is not discernible. $B$ : trophozoites attached to monolayer of chick epithelial lung cells. Arrow at attachment site. $C$ : detaching trophozoite with surface convolutions, suggesting early development into the cyst form. $D$ : cyst forms $(C)$. Two sporozoites $(S)$ are visible. $E$ : excystment. Early stage shows sporozoite emerging through cell wall. $F$ : excystment. Later stage shows the sporozoites in $E$ released or small trophozoite. $G$ : mature and inactive cyst; contains pleomorphic sporozoites. $H$ : cyst of $P$. carinii obtaned directly from infected lung to show in comparison to organism in culture. Compare to $C$. 

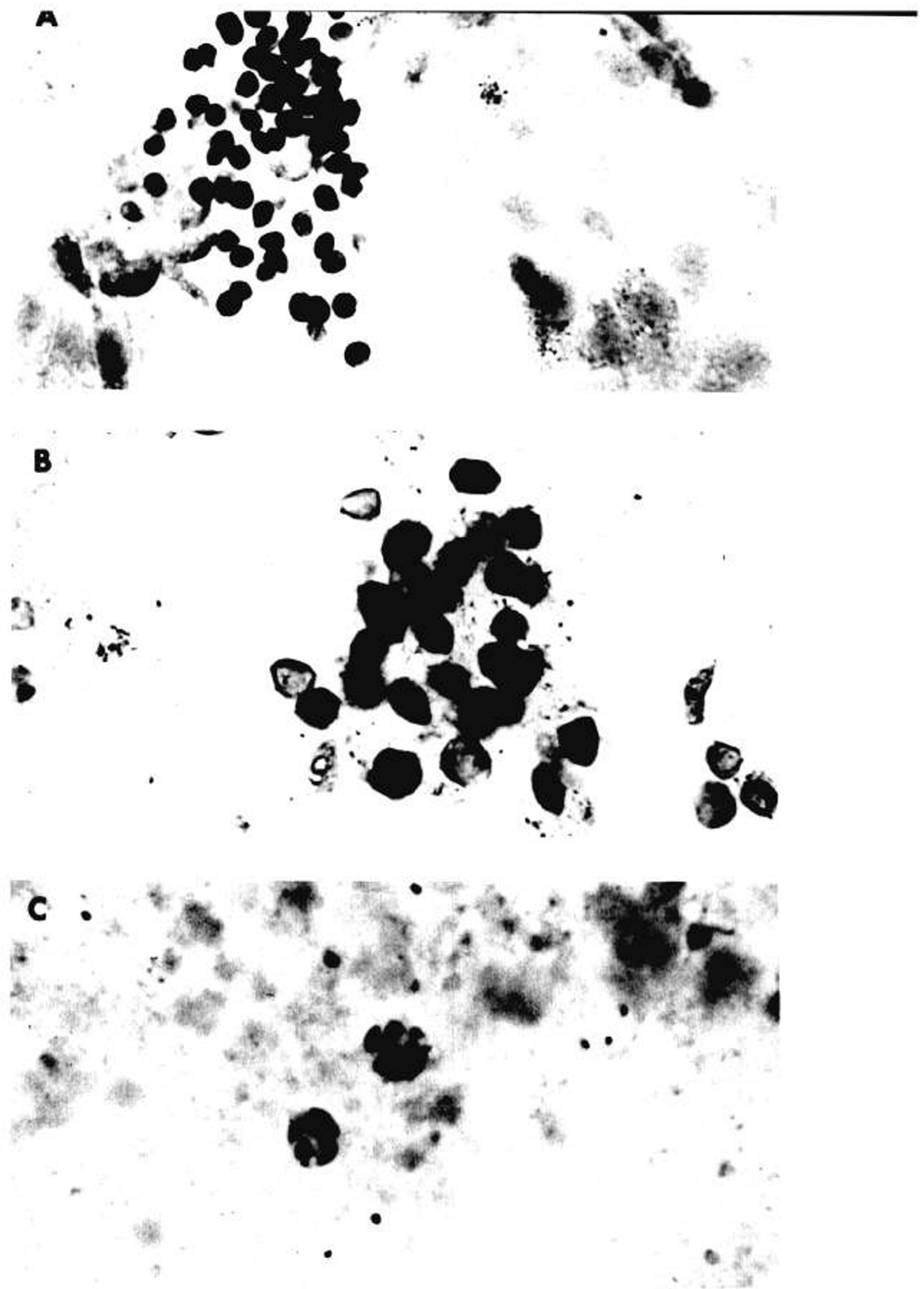

Fig. 4. Pneumocystis carinii after third passage in chick epithelial lung (CEL) cell cultures. $\dot{A}$ : stained with Gomori's methenamine silver nitrate method demonstrating the clusters of dark, round to oval cysts immediately surrounded by degenerated host cells. The CEL cells were counterstained with hematoxylin and eosin (magnification, $\times 800$ ). B: stained with toluidine blue $O$. Only $P$. carinii cysts are stained (magnification, $\times 1,530)$. $C$ : stained with polychrome methylene blue. The sporozoites are stained and are pleomorphic. The cyst wall is unstained (magnification, $\times 1,980$ ). 
gradually declined. Thus, evidence was obtained that $P$. carinii is capable of significant, although not indefinite, growth in the CEL cell culture system

That cysts in the original inoculum are not merely being transferred from one passage to the next is demonstrated by the experiment where trophozoites, relatively free of cysts (less than 10 ), were inoculated into CEL cell culture and $2.8 \times 10^{3}$ cysts were identified in the second passage. Typical CPE occurred. Furthermore, in all the cell-free media studied, no increase in the number of cysts occurred.

It was also demonstrated that specific $P$. carinii antiserum and pentamidine isethionate inhibited the growth of the organisms in CEL cell culture. Incubation of cysts with serum containing no detectable antibody to $P$. carinii did not adversely affect the yield. These data thus support the contention that the organism under study is $P$. carinii and that in vitro multiplication occurred.

The culture of murine $P$. carinii utilizing 3-day passage intervals with freezing of inocula between passages resulted in a modest 8-fold increase in the number of cyst forms occurring in

Table 5. Effect of specific antiserum on growth of Pneumocystis carinii' in chick epithelial lung cell culture: $C y$ st yield per triplicate culture

\begin{tabular}{|c|c|c|c|}
\hline \multirow{2}{*}{$\begin{array}{l}\text { Hours } \\
\text { postin- } \\
\text { ocula- } \\
\text { tion }\end{array}$} & \multicolumn{3}{|c|}{ Organisms incubated in } \\
\hline & Fetal bovine serum & $\begin{array}{l}\text { Human antiserum } \\
\text { with } P \text {. carinii anti- } \\
\text { body }\end{array}$ & $\begin{array}{l}\text { Human serum with- } \\
\text { out } P \text {. carinii anti- } \\
\text { body }\end{array}$ \\
\hline 0 & $8.0 \times 10^{4}$ & $8.0 \times 10^{4}$ & $8.0 \times 10^{4}$ \\
\hline 4 & $8.6 \times 10^{4}$ & $7.5 \times 10^{4}$ & $8.6 \times 10^{4}$ \\
\hline 18 & $10.0 \times 10^{4}$ & $7.2 \times 10^{4}$ & $10.2 \times 10^{4}$ \\
\hline 25 & $15.5 \times 10^{5}$ & $7.1 \times 10^{4}$ & $15.3 \times 10^{5}$ \\
\hline 51 & $12.8 \times 10^{5}$ & $6.8 \times 10^{4}$ & $13.8 \times 10^{5}$ \\
\hline
\end{tabular}

${ }^{1}$ Inoculum $=8.0 \times 10^{4}$ cysts/culture. the second passage (Fig. 1). It is possible that freezing may have killed an indeterminate number of organisms. Thereafter, the titer diminished gradually with only an insignificant increase in the sixth passage. This pattern is reminiscent of early in vitro studies of growth characteristics of some protozoan parasites, such as certain Plasmodium species (3), where the number of organisms diminishes after an initial increase. However, with recent improvements in technique Plasmodium falciparum can be maintained in continuous culture (35). Reasons for the failure of $P$. carinii to achieve growth in vitro for indefinite intervals are not known. This may involve a lack of complete adaptation to the CEL cell culture environment. Nevertheless, the CEL cell system provides a base for experimental modifications.

The relative distribution of cysts between media and cells on coverslips in Leighton tubes during an 8-day passage was determined (Fig. 2). This experiment provided a general pattern of the cyclic nature of the organism in culture. The rapid increase in the number of cysts during the first $24 \mathrm{hr}$ postinoculation probably represents the maturation of trophozoites in the inoculum into cyst forms. The subsequent decline in cysts is probably due to the release of a culture generation of trophozoites. There occurs then a progressive increase in the number of cysts which may reflect a maturation of the second generation of trophozoites until a plateau or stationary phase is reached. The ratio of cysts to trophozoites and the viability of the organisms in the original inocula were unknown, since the trophozoites cannot be counted. However, experiments carrying the organisms through several passages have been repeated many times using infected lungs from different rats as sources of inoculum and the results are remarkably similar. This indicates that cyst counts provide a reliable measure of viability, although probably a relative one. Evidence to support this view is provided by the experiment in which purified trophozoites gave rise to cysts during serial passage, with the development of typical CPE.

It should be emphasized that the Sykes-Moore chamber stud-
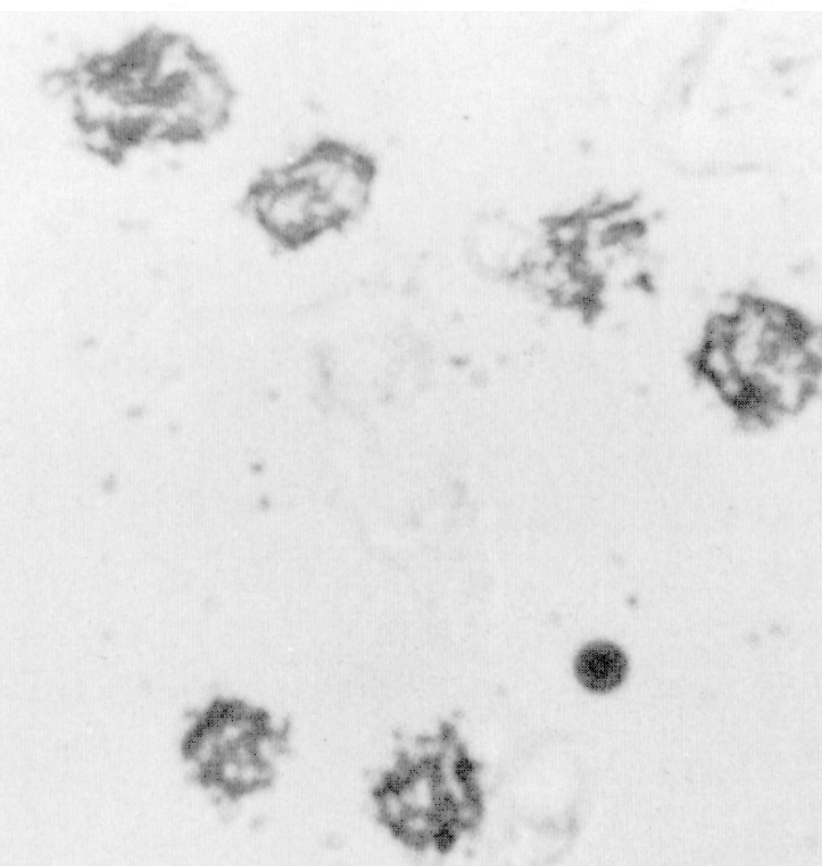

Fig. 5. Autoradiograph of $\left[{ }^{3} \mathrm{H}\right]$ uridine-labeled Pneumocystis carinii cyst. 
PIFER, HUGHES, AND MURPHY, JR.
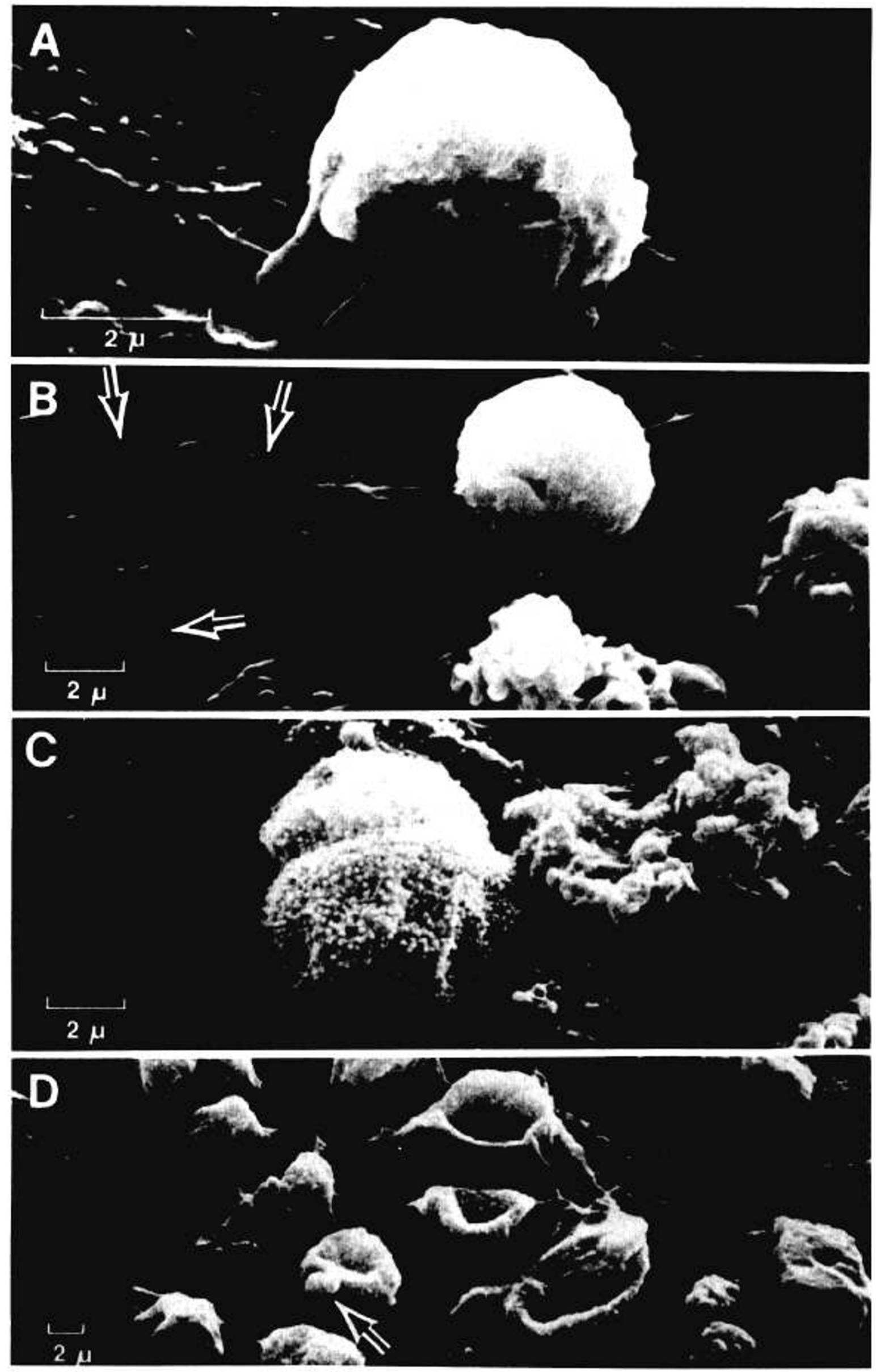


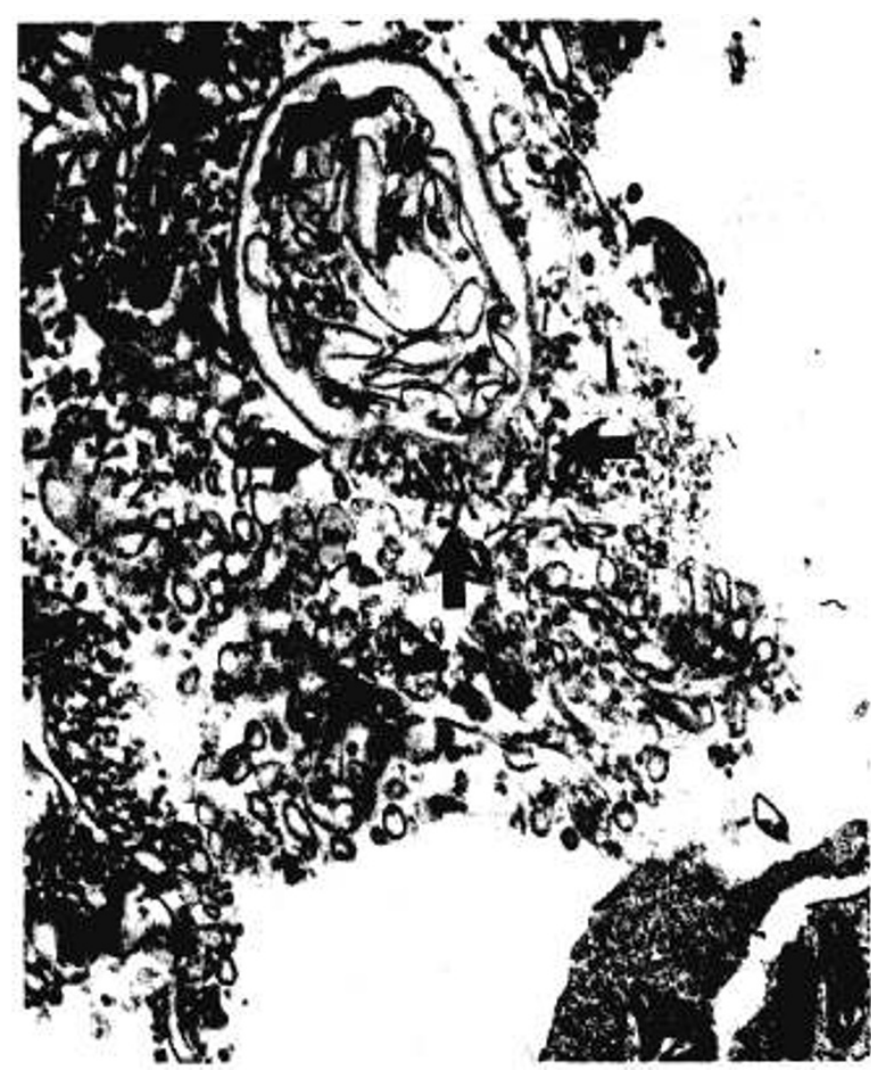

Fig. 7. Transmission electronmicrograph of Pneumocystis carinii cyst in chick epithelial lung cell culture. (The bar denotes $1 \mu \mathrm{m}$.) Detached early cyst, $2 \mathrm{hr}$ postinoculation. The cyst contains multiple laminar arrays of smooth membranes and an apical (arrows) aggregation of tubules continuous with the cyst wall. No sporozoites are discernible. A portion of a chick epithelial lung cell is seen in the lower right corner of the micrograph (original magnification, $\times 4,250$ ).

ies concentrated upon single organisms as opposed to populations profiled in the Leighton tube experiments. No temporal relationship can be made between these two separate experiments.

The life cycle observed in culture is similar to that deduced from sections of infected lung specimens by Vavra and Kucera (37), Campbell (6), Barton and Campbell (2), Kim, et al. (22), and others. However, we were unable to demonstrate multiplication of the trophozoite by fission or budding. In our observations, extracystic formation of sexual gametes or conjugation were not encountered. It is possible that such a stage in the life cycle of the organism could occur in the natural host or that it was unrecognizable in the system studied.

The unique attachment of trophozoites to host CEL cells is an interesting phenomenon. Using electron microscopy, Barton and Campbell (2) have demonstrated in the murine host and Hughes et al. (21) have shown in the human host the characteristic proximity of trophozoites to alveolar septal wall cells of lungs infected with $P$. carinii. These trophozoites were demonstrated (2) to have a pellicle which frequently evaginated into filopodia or pseudopodia. Ham et al. (20) have observed microvillous tubular structures which appear to anchor the organism to the alveolar wall. In Barton and Campbell's study (2), cytosomes, Golgi apparatus, and lysosomal structures were not found, suggesting that $P$. carinii is without the organelles needed to supply nutritional resources usually associated with phagocytosis or hydrolytic processes. Furthermore, their finding of the presence of neutral adenosine 5'-triphosphatase activity in the pellicles of free "trophozoites" suggests that sodium and potassium transport takes place across this site. We have shown by autoradiography that $P$. carinii incorporated $\left[{ }^{3} \mathrm{H}\right] \mathrm{TdR},\left[{ }^{3} \mathrm{H}\right] \mathrm{UR}$, and ${ }^{3} \mathrm{H}-$ amino acids from labeled CEL cells demonstrating active DNA, RNA, and protein synthesis within the cyst and indicating a metabolic interaction between the host cell and the parasite. It seems likely, therefore, that the attachment of the trophozoite to the host CEL cell represents a means by which the organism obtains essential nutrients for growth. This transport must require viable intact host cells since growth of the organism did not occur with freeze-killed CEL cells. Intracellular parasitism was not encountered in this culture system nor has it been recognized in natural hosts except during defensive phagocytosis by alveolar macrophages after which digestion of the organism occurs.

The point at which the trophozoite becomes a cyst is not precisely identifiable in culture and the definitions we have used have been somewhat arbitrary in this regard. It is possible that early sporozoite formation may occur before detachment from the host cell, yet this was not detectable by the methods used.

The replicative cycle in the Sykes-Moore chamber required 4$6 \mathrm{hr}$. However, this cannot be directly related to the growth patterns shown in Figure 2 since the cultures were not synchronous and organisms were in various stages of growth or dormancy.

In conclusion, $P$. carinii from murine and human sources has been propagated in CEL cells for a limited period of time. The life cycle and a 100-fold multiplication of cysts were observed. The vegetative trophozoite attaches to the host cell, probably for the import of essential nutrients and growth factors. After detachment the cyst enlarges and the host cell degenerates. Sporozoites form within the cyst until a maximum number of eight is attained in the mature cyst. Excystment occurs through single or multiple sites in the cyst wall after which the released trophozoite attaches to a host cell. No active mechanism for motility was demonstrated, but further studies are necessary, and now possible, to delineate the taxonomic position of $P$. carinii.

The culture system described provides an excellent source of $P$. carinii organisms to investigate the ultrastructural and biochemical characteristics of this unique organism and for the development of methods for the study of antimicrobial agents and the detection and quantitation of specific antibody in sera of patients. When reliable serologic methods are available, epidemiologic studies can be undertaken to further elucidate the nature of this infection in man.

\section{CONCLUSION}

$P$. carinii, derived from human and murine sources, was propagated in vitro in primary embryonic CEL cells. Serial passage of the organisms at 3 -day intervals over a period of 12 days resulted in a 100 -fold increase in the number of cyst forms. Additionally, inoculation of trophozoites alone yielded $2.8 \times 10^{3}$ cysts in the second passage. Indefinite in vitro growth of the organism was not achieved. The isolated agent was identified as $P$. carinii by its

Fig. 6. Scanning electronmicrographs of Pneumocystis carinii in chick epithelial lung (CEL) cell culture. (Magnification: The white bar denotes 2 $\mu \mathrm{m}$.) $A$ : trophozoite with pseudopodal and tubular extension on the surface of the CEL cell. From cultures $4 \mathrm{hr}$ after inoculation. (Angle of tilt $=$ $20^{\circ}$; original magnification, $\times 10,000$.) B: large trophozoite, $5 \mu \mathrm{m}$ in diameter, from cultures $4 \mathrm{hr}$ after inoculation, showing the diffuse network of tubules (arrows) between the organism and the host cell. (Angle of tilt $=35^{\circ}$; original magnification, $\times 5,000$.) $C$ : cyst, approximately $7 \mu \mathrm{m}$ in diameter with diffuse short microvillous surface projections of uniform size, $8 \mathrm{hr}$ post-inoculation of CEL cells. The conglomerate to the right of the cyst is not identifiable but may represent excysted material. (Angle of tilt $=20^{\circ}$; original magnification, $\times 5,000$.) $D$ : multiple $P$. carinii organisms on the surface of CEL cells $8 \mathrm{hr}$ postinoculation in various stages of attachment. The clearly attached forms are concave and may represent precyst forms before intracystic structures have developed. One organism (arrow) approximately $6 \mu \mathrm{m}$ in diameter with no visible attachment may be in the early phase of excystment. (Angle of tilt $=45^{\circ}$; original magnification, $\times 2,500$ ). 
tinctorial and morphologic appearance with polychrome, toluidine blue $O$, and methenamine silver nitrate stains and immunologically by indirect fluorescein-labeled antibody reaction to $P$. carinii antisera. Specific antisera and pentamidine isethionate inhibited growth of the organism in culture. Active RNA, DNA, and protein synthesis was demonstrated by isotopic methods. In the reproductive cycle a vegetative cell designated "trophozoite" attached by tubular expansions to the host CEL cell, probably for the transport of essential nutrients, and then detached without entering the host cell. Sporozoites developed within the detached young cyst, reaching a maximum of eight within the mature cyst. Excystment occurred through single or multiple sites in the cyst wall, after which the released trophozoite attached to a new host cell.

\section{REFERENCES AND NOTES}

1. Balamuth, W.: Improved egg yolk infusion for cultivation of Entamoeba histolytica and other intestinal protozoa. Amer. J. Clin. Pathol., 16: 380 (1946).

2. Barton, E. G., and Campbell, W. G.: Pneumocystis carinii in lungs of rats treated with cortisone acetate. Amer. J. Pathol., 54: 209 (1969).

3. Bishop, A.: Problems in the cultivation of some parasitic protozoa. Advan. Parasitol., 5: 93 (1967).

4. Blair, G., Lennette, C., and Truant, F.: Manual of Clinical Microbiology. Amer. Soc. Microbiol., p. 25 (1970).

5. Campbell, W. G.: Ultrastructure of Pneumocystis in human lung: Life cycle in human pneumocystosis. Arch. Pathol., 93: 312 (1972).

6. Carini, A.: Formas de eschizogonia do Trypanozoma lewisi. Commun. Soc. Med. Sao Paulo, p. 204, Aug. 16 (1910).

7. Chagas, C.: Nova tripanozomiaza humana. Estudos sobre a morfologia e o ciclo evolutivo do Schizotrypanum cruzi n. gen., n. sp., agente etiologio de nova entidade morbida de homen. Mem. Inst. Oswaldo Crus (Rio), 1: 159 (1909).

8. Chalvardjian, A. M., and Grawe, L. A.: A new procedure for the identification of Pneumocystis carinii cysts in tissue sections and smears. J. Clin. Pathol., 16: 383 (1963).

9. Chang, S. L.: Studies of haemoflagellates. I. A semisolid medium and fluid medium with a solid base for growing various strains of Leishmania and Trypanosoma cruzi. J. Infect. Dis., 80: 164 (1947)

10. Csillag, A.: Contribution to taxonomical classification of the so-called Pneumocystis carinii. Acta Microbiol. Acad. Sci. Hung., 4: 1 (1957).

11. Csillag. A., and Brandstein, L.: The role of Blastomyces species in the genesis of interstitial plasmacellular pneumonia of the premature infant: A preliminary report. Acta Microbiol. Acad. Sci. Hung., 1: 525 (1954).

12. Csillag, A., and Brandstein, L.: The role of a Blastomyces in the aetiology of interstitial plasmocytic pneumonia of the premature infant. Acta Microbiol. Acad. Sci. Hung., 2: 179 (1954).

13. Darlington, R. W., Portner, A., and Kingsbury, D. W.: Sendai virus replication: An ultrastructural comparison of productive and abortive infections in avian cells. J. Gen. Virol., 9: 169 (1970).

14. Delanoe, P., and Delanoe, M.: Sur les rapporte des kystes de carinii le Trypanosoma lewisi. C. R. Acad. Sci., 155: 658 (1912)

15. Delanoe, P., and Delanoe, M.: De la rarete de Pneumocystis carinii chez les cobayes de la region de Paris; absense de kysts chez d'autres animaux lapin, grenouille, 3 anguilles. Bull. Soc. Path. Exot., 7: 271 (1914).

16. Diamond, L. S.: Axenia culture for trichomonads (Trichomonas vaginalis). J. Parasitol. 43: 488 (1957)

17. Fletcher, S.: Indirect fluorescent antibody technique in the serology of Toxoplasma gondii. J. Clin. Pathol., 18: 193 (1965)

18. Frenkel, J. K., Good, J. T., and Shultz, J. A.: Latent Pneumocystis infection of rats, relapse and chemotherapy. Lab. Invest., 15: 1559 (1966).

19. Gajdusek, D. C.: Pneumocystis carinii-etiologic agent of interstitial plasma cell pneumonia of premature and young infants. J. Pediat., 19: 543 (1957).

20. Ham, E. K., Greenberg, S. D., Reynolds, R. C., and Singer, D. B.: Ultrastructure of Pneumocystis carinii. Exp. Mol. Pathol. 14: 362 (1971)

21. Hughes, W. T., Price, R. A., Kim, H. Y., Coburn, T. P., Grigsby, D., and
Feldman, S.: Pneumocystis carinii pneumonitis in children with malignancies. J. Pediat., 82: 404 (1972)

22. Kim, H. K., Hughes, W. T., and Feldman, S.: Studies of morphology and immunofluorescence of Pneumocystis carinii. Proc. Soc. Exp. Biol. Med., 141: 304 (1972).

23. Lim, S. K., Eveland, W. C., and Porter, R. J.: Development and evaluation of a direct fluorescent antibody method for the diagnosis of Pneumocystis carinii infections in experimental animals. Appl. Microbiol., 26: 666 (1973).

24. Luft, J. H.: Improvements in epoxy resin embedding methods. J. Biophys. Biochem. Cytol., 9: 409 (1961).

25. Merchant, D. J., Kahn, R. J., and Murphy, W. A.: Handbook of Cell and Organ Culture, p. 200 (Burgess, Minneapolis, 1964)

26. Murphy, M. J. Jr., Bertles, J. F., and Gordon, A. S.: Identifying characteristics of the haematopoietic precursor cell. J. Cell. Sci., 9: 23 (1971)

27. Newton, B. A.: A synthetic growth medium for the trypanosomid flagellate Strigomonas (Herpetomonas) oncopelti. Nature, 177: 279 (1956).

28. Pan, C. T.: Cultivation of the leismaniform stage of Trypanosoma cruzi in cellfree media at different temperatures. Amer. J. Trop. Med., 17: 823 (1968).

29. Pan, C. T.: Cultivation and morphogenesis of Trypanosoma cruzi in improved media. J. Protozool., 18: 556 (1971).

30. Schoefl, G. I.: The migration of lymphocytes across the vascular endothelium in lymphoid tissue: A re-examination. J. Exp. Med., 136: 568 (1972).

31. Sheldon, W. H.: Pulmonary Pneumocystis carinii infection. J. Pediat., 61: 780 (1962).

32. Simon, H.: Die sogenannte Pneumocystis carinii eine besondere vegatationsform des Soor. Naturwissenschaften, 40: 625 (1953).

33. Sykes, J. A., and Moore, E. B.: A simple tissue culture chamber. Tex. Rep. Biol. Med., 18: 288 (1960).

34. Tobie, E. J., Brand, T., and Mehlman, B.: Culture and physiologic observations on Trypanosoma rhodesiense and Trypanosoma gambiense. J. Parasitol., 36: 48 (1950).

35. Trager, W., and Jensen, J. B.: Human malaria parasites in continuous culture. Science, 193: 673 (1976).

36. Vanek, J., and Jirovec, O.: Parasitare pneumonie. "Interstitielle" plasmazellen-pneumonie der fruhgeborenen, verursacht durch Pneumocystis carinii. Zentralbl. Bakt. I Abt. Orig. Bd., 158: 120 (1952).

37. Vavra, J., and Kucera, K.: Pneumocystis carinii Delanoe, its ultrastructure and ultrastructure affinities. J. Protozool., 17: 463 (1970).

38. Walker, E. L.: The schizogony of Trypanosoma evansi in the spleen of the vertebrate host. Phillipine J. Sci., 7: 53 (1912).

39. Wallace, F. G.: Cultivation of Trypanosoma ranarum on liquid medium. J. Protozool., 3: 47 (1956)

40. Ivan Sorvall, Inc., Norwalk, Conn.

41. Grand Island Biological Co., Grand Island, N. Y.

42. Worthington Biochemicals, Inc., Freehold, N. J.

43. Flow Laboratories, Rockville, Md.

44. Falcon Plastics, Cockeysville, Md.

45. BioQuest, Becton Dickinson \& Co., Cockeysville, Md.

46. Miles Laboratories, Inc., Kankakee, III.

47. May and Baker, Ltd., Dagenham, Eng.

48. Schwartz/Mann, Inc., Orangeburg, N. J.

49. Eastman Kodak Co., Rochester, N. Y.

50. Siemens Corp., Iselin, N. J.

51. Philips Electronics Industries, Mt. Vernon, N. Y

52. E. Leitz Co., New York, N. Y.

53. This work was supported by Research Grant Al-11277 from the National Institutes of Allergy and Infectious Diseases, Childhood Cancer Research Center Grant CA-08480 from the National Cancer Institute, National Institutes of Health, and by ALSAC.

54. We acknowledge the valuable technical assistance of Mrs. Diane Woods and Mr. Kenneth McCorkle and the suggestions of Dr. Allan Granoff for preparation of the manuscript, and the help of Mr. J. D. Rodgers of Philips Electronic Instruments, Inc. Dr. Stephen George provided biostatistic analysis of the data.

55. Requests for reprints should be addressed to: W. T. Hughes, M.D., Infectious Diseases Service, St. Jude Children's Research Hospital, 332 N. Lauderdale, Memphis, Tenn. 38101 (USA).

56. Received for publication November 21,1975

57. Accepted for publication September 22, 1976. 